Marvin A. Sweeney

\title{
Reading Prophetic Books
}

Form, Intertextuality, and Reception in Prophetic and Post-Biblical Literature

[Prophetenbücher deuten. Form, Intertextualität und Rezeption in prophetischer und nachbiblischer Literatur.]

Veröffentlicht auf Englisch.

Marvin A. Sweeney baut in dieser Monographie auf seinem früheren Werk »Form and Intertextuality in Prophetic and

MARVIN A. SWEENEY

Reading Prophetic Books

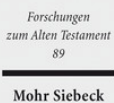

2014. XVI, 408 Seiten. FAT 89

ISBN 978-3-16-152377-9

DOI 10.1628/978-3-16-152377-9

eBook PDF $174,00 €$

ISBN 978-3-16-152374-8

Leinen $174,00 €$
Apocalyptic Literature« (FAT 45, 2005) auf. Er stellt weitere Studien vor, die sich mit verschiedenen Schlüsselthemen befassen, einschließlich der Interpretation von Prophetenbüchern in ihrer endgültigen literarischen Form und der Bedeutung der Textversion für die Lektüre der Prophetenbücher. Außerdem untersucht er das intertextuelle Verhältnis zwischen den Propheten und anderen biblischen oder nach-biblischen Werken der Literatur und die Rezeption der Prophetenbücher. Neben einer Einführung, die die methodologische Perspektive darstellt, enthält der Band den titelgebenden Aufsatz »Prophetenbücher deuten«, sowie eine Auswahl von Aufsätzen zu Jesaja, Jeremia (sowohl im masoretischen, als auch im Septuaginta-Text), Ezechiel, zu einzelnen Werken aus dem Zwölfprophetenbuch und zur Deutung biblischer Texte in Qumran, in rabbinischer und in der Targumliteratur.

Marvin A. Sweeney Born 1953; 1983 PhD from Claremont Graduate School; Professor of Hebrew Bible at Claremont Lincoln University and Claremont School of Theology and Professor of Tanak at the Academy for Jewish Religion California.

Jetzt bestellen:

https://mohrsiebeck.com/buch/reading-prophetic-books-9783161523779?no_cache=1

order@mohrsiebeck.com

Telefon: +49 (0)7071-923-17

Telefax: $+49(0) 7071-51104$ 